\title{
The Mechanosensitivity of Mouse Colon Afferent Fibers and Their Sensitization by Inflammatory Mediators Require Transient Receptor Potential Vanilloid 1 and Acid-Sensing Ion Channel 3
}

\author{
R. Carter W. Jones III, ${ }^{1,2}$ Linjing Xu, ${ }^{2}$ and G. F. Gebhart ${ }^{2}$ \\ ${ }^{1}$ Medical Scientist Training Program and ${ }^{2}$ Department of Pharmacology, Carver College of Medicine, The University of Iowa, Iowa City, Iowa 52242
}

\begin{abstract}
Mechanical hypersensitivity of the colon underlies in part the chronic abdominal pain experienced by patients with irritable bowel syndrome, yet the molecules that confer mechanosensitivity to colon sensory neurons and their contribution to visceral pain are unknown. We tested the hypothesis that transient receptor potential vanilloid 1 (TRPV1) and acid-sensing ion channel 3 (ASIC3) are peripheral mechanosensors in colon afferent neuronal fibers that mediate visceral nociceptive behavior in mice. Visceral nociception, modeled by the visceromotor response to colorectal distension, and colon afferent fiber mechanosensitivity were assessed in control (C57BL/6) mice and two congenic knock-out mouse strains with deletions of either TRPV1 or ASIC3. Phasic colon distension (15-60 $\mathrm{mmHg}$ ) produced graded behavioral responses in all three mouse strains. However, both TRPV1 and ASIC3 knock-out mice were significantly less sensitive to distension, with an average response magnitude only 58 and $50 \%$ of controls, respectively. The behavioral deficits observed in both strains of knock-out mice were associated with a significant and selective reduction in afferent fiber sensitivity to circumferential stretch of the colon, an effect that was mimicked in control preparations by pretreatment with capsazepine, a TRPV 1 antagonist, but not amiloride, a nonselective ASIC antagonist (both $500 \mu \mathrm{M}$ ). In addition, whereas stretch-evoked afferent fiber responses were enhanced by chemical inflammatory mediators in control mice, this effect was differentially impaired in both knock-out mouse strains. These results demonstrate a peripheral mechanosensory role for TRPV1 and ASIC3 in the mouse colon that contributes to nociceptive behavior and possibly peripheral sensitization during tissue insult.
\end{abstract}

Key words: VR1; pain; primary afferent; mechanosensation; hypersensitivity; colon; mouse

\section{Introduction}

Mechanical distension of hollow organs such as the colon is uniquely capable of producing reports of pain in humans and pseudaffective nociceptive behavior in animals (for review, see Gebhart et al., 2004). Peripheral terminals of sensory neurons innervating the colon are equipped to detect a variety of mechanical stimuli, including organ distension (Su and Gebhart, 1998) and circumferential stretch of the muscle layers (Lynn and Blackshaw, 1999), and the sensitization of colon afferent fiber function contributes to the mechanical hypersensitivity and abdominal pain of patients with irritable bowel syndrome (Lembo et al., 1994). However, the molecules responsible for mechanosensation and sensitization in the viscera are unknown but present promising targets for novel treatments of visceral pain.

Recently, transient receptor potential vanilloid 1 (TRPV1)

Received Feb. 21, 2005; revised 0ct. 12, 2005; accepted 0ct. 15, 2005.

This work was supported by National Institute of Neurological Disorders and Stroke Grants R01-NS-19912 and F31-NS-46941. We acknowledge M. Price and M. Welsh for graciously providing the congenic ASIC3 knock-out mice used in this study and M. Burcham for help with manuscript preparation.

Correspondence should be addressed to G. F. Gebhart, Department of Pharmacology, 2-302 Bowen Science Building, The University of lowa, lowa City, IA 52242. E-mail: gf-gebhart@uiowa.edu.

DOl:10.1523/JNEUROSCI.0703-05.2005

Copyright $\odot 2005$ Society for Neuroscience 0270-6474/05/2510981-09\$15.00/0 and acid-sensing ion channel 3 (ASIC3) have emerged as potential mechanosensors that mediate pain associated with gastrointestinal disease. Protein expression levels of both TRPV1 and ASIC3 are increased in biopsy specimens from patients with inflammatory bowel disease, a condition in which visceral pain is a prominent symptom (Yiangou et al., 2001a,b). In animals, TRPV1 is present in neurons throughout the viscera (Birder et al., 2001; Ward et al., 2003), in which it has been shown to participate in mechanosensation in the small intestine (Rong et al., 2004) and bladder (Birder et al., 2002). ASIC3 is also expressed in sensory neurons (Alvarez de la Rosa et al., 2002) and has been implicated in mechanosensation in the skin (Price et al., 2001). The mechanosensory function of TRPV1 and ASIC3 in peripheral neurons appears to be especially important after tissue injury because mechanical hypersensitivity after inflammation of the bladder or muscle is partially mediated by TRPV1 (Dinis et al., 2004) and ASIC3 (Sluka et al., 2003), respectively. Neither protein has been directly implicated in colon mechanosensation, and therefore their contribution to pain from this organ is unclear.

The hypothesis of these experiments is that TRPV1 and ASIC3 mediate visceral pain by contributing to the peripheral detection of mechanical stimuli in the colon. To test this hypothesis, we used a combination of behavioral and electrophysiological tech- 
niques in congenic knock-out mice with genetic deletion of TRPV1 or ASIC3 to overcome the lack of specific pharmacologic tools to study these proteins. We found significant deficits in visceral nociception and impairments in the mechanosensory properties of stretch-sensitive colon afferent neuronal fibers in both knock-out mice strains. In addition, whereas the function of these fibers could be sensitized by chemical inflammatory mediators in control mice, gene deletion differentially affected sensitization in TRPV1 and ASIC3 knock-out mice. These results support a mechanosensory role for TRPV1 and ASIC3 in the mouse colon and demonstrate that mouse colon sensory neurons can be sensitized by exposure to chemical inflammatory mediators in a TRPV1- and ASIC3-dependent manner.

\section{Materials and Methods}

All procedures were approved by the Institutional Animal Care and Use Committee of The University of Iowa (Iowa City, IA).

Animals. Adult male mice weighing 20-30 g from the following mouse strains were used in these experiments: congenic TRPV1 knock-out (The Jackson Laboratory, Bar Harbor, ME), congenic ASIC3 knock-out (graciously provided by M. Price and M. Welsh, The University of Iowa, Iowa City, IA), and C57BL/6 (Taconic Farms, Germantown, NY). C57BL/6 mice were used as a wild-type control for all experiments because both knock-out mouse strains are congenic on this genetic background (backcrossed $\geq 10$ generations). The experimenter was blinded to animal genotype during behavioral and electrophysiological experiments.

Electromyographic electrode implantation. To record the visceromotor response (VMR) to colorectal distension (CRD), electromyographic (EMG) electrodes were surgically implanted in the abdominal musculature. Mice were anesthetized by subcutaneous injection of ketamine/ xylazine (87.5/12.5 mg/kg, i.p.), the right or left musculature was exposed through an incision made on the abdomen, and the bare ends of two lengths of Teflon-coated stainless steel wire (Cooner Wire Sales, Chatworth, CA) were inserted into the abdominal muscles and secured in place with 5-0 silk sutures. The other wire ends were tunneled subcutaneously to a small incision made on the nape of the neck and externalized for access during behavioral testing. A minimum of $3 \mathrm{~d}$ were allowed for recovery from surgery before initiating the distension testing protocol.

Animal preparation for distension testing. On the day of testing, mice were briefly sedated ( $<5 \mathrm{~min}$ ) with halothane $\left(2 \%\right.$ delivered in $100 \% \mathrm{O}_{2}$ at $2 \mathrm{~L} / \mathrm{min}$; Halocarbon Laboratories, River Edge, NJ) for balloon insertion. The CRD balloon consisted of a custom-made polyethylene plastic cylinder (length, $1.5 \mathrm{~cm}$; diameter, $0.9 \mathrm{~cm}$ ) secured with 5-0 silk sutures to the perforated end of a $20 \mathrm{~cm}$ length of polytetrafluoroethylene- 24 thin-walled tubing (Cole-Parmer Instrument, Vernon Hills, IL). The balloon was protected during insertion by a sheath made from a $6 \mathrm{~cm}$ length of polyethylene- 240 tubing slit longitudinally to accommodate the girth of the balloon. The balloon and sheath were coated with lubricant, inserted transanally until the proximal end of the balloon was 0.5 $\mathrm{cm}$ from the anal verge (total balloon insertion, $2 \mathrm{~cm}$ ), the sheath was removed, and the balloon was secured to the mouse's tail with tape. Halothane was discontinued, and mice were placed inside a restraint device (a modified, plastic $60 \mathrm{ml}$ syringe with the syringe port removed, a window created to allow access to the externalized ends of the electrodes, and shortened to $8 \mathrm{~cm}$ in length). The device was covered with a black sock while the animal was allowed to recover fully from the halothane anesthesia (30 $\mathrm{min})$ and throughout the duration of behavioral testing.

$E M G$ recording and $C R D$ testing protocols. CRD testing was performed as described previously (Kamp et al., 2003). Briefly, EMG activity was recorded during phasic balloon inflation to $15-60 \mathrm{mmHg}$. Balloon inflation was achieved by connecting the balloon to a large tank of compressed nitrogen. Inflation pressures were adjusted via the tank regulator, and gas flow through the system was controlled by a custom-made distension control device (The University of Iowa Medical Instruments, Iowa City, IA) to enable computer triggering of balloon inflation. Each distension lasted $20 \mathrm{~s}$, each pressure was tested three times, and $4 \mathrm{~min}$ separated each distension.
EMG electrode activity was amplified, filtered, and recorded on a personal computer with Spike 2 software (Cambridge Electronic Design, Cambridge, UK) for off-line analysis. CRD responses were quantified by using the suprathreshold spike method. Threshold EMG activity was set at $300 \mu \mathrm{V}$, above the average background activity of mice in our hands. The number of times that EMG activity surpassed the preset threshold value during the balloon inflation period was counted and used as a reflection of distension-evoked behavioral responses.

Mouse colon-pelvic nerve preparation. A total of 42 control (C57BL/6), 20 TRPV1 knock-out, and 22 ASIC3 knock-out mice were killed for electrophysiological experiments. As described previously (Brierley et al., 2004), mice were killed by $\mathrm{CO}_{2}$ asphyxiation, the abdominal cavity was opened, and the body was submerged during dissection in ice-cold, modified Krebs' solution [in mm: $117.9 \mathrm{NaCl}, 4.7 \mathrm{KCl}, 25 \mathrm{NaHCO}_{3}, 1.3$ $\mathrm{NaH}_{2} \mathrm{PO}_{4}, 1.2 \mathrm{MgSO}_{4}\left(\mathrm{H}_{2} \mathrm{O}\right)_{7}, 2.5 \mathrm{CaCl}_{2}, 11.1$ D-glucose, 2 sodium butyrate, and 20 sodium acetate] that was bubbled with carbogen $(95 \%$ $\mathrm{O}_{2} / 5 \% \mathrm{CO}_{2}$ ) and contained $1 \mu \mathrm{M}$ nifedipine, an L-type calcium channel blocker to inhibit smooth muscle contractions, and $3 \mu \mathrm{m}$ indomethacin, a prostaglandin synthesis inhibitor to suppress the release of endogenous prostaglandins. The distal $6 \mathrm{~cm}$ of the descending colon and rectum with pelvic nerves attached were dissected free from the abdomen, the colon was opened longitudinally along the antimesenteric border, and the entire preparation was placed in a custom-built organ-nerve bath (Danz Instrument Service, Adelaide, South Australia, Australia). The colon was pinned flat, mucosal side up, to the clear Sylgard (Dow Corning, Midland, MI) base of an organ chamber continually perfused at rate of 10 $\mathrm{ml} / \mathrm{min}$ with carbogenated, modified Krebs' solution maintained at 33$34^{\circ} \mathrm{C}$. The pelvic nerves were passed into an adjacent recording chamber filled with mineral oil through a small hole in a gate separating the two chambers and sealed with petroleum jelly.

Single-fiber electrophysiological recordings. One at a time, the pelvic nerves were cleared of connective tissue, the nerve sheath was gently pulled back, and each nerve was split into 10-12 smaller bundles with fine forceps on a glass plate fixed to the floor of the recording chamber. Each bundle was draped across a platinum recording electrode, with a reference electrode resting in a small puddle of Krebs' solution on the glass plate, and tested for mechanosensitive afferent fibers by searching with a soft brush for receptive fields along the entire length of the colon and attached mesentery. Bundles were either discarded if they exhibited no brush-evoked activity or split further if they contained more than two readily distinguished single units. Electrical signals from the recording electrode were amplified and filtered with a differential amplifier and sampled at a rate of $20 \mathrm{kHz}$ using a 1401 interface device (Cambridge Electronic Design). Data were stored on a personal computer for off-line analysis. The electrical signal was also fed to an audio monitor to facilitate real-time detection and discrimination of active units.

Mechanical and chemical testing of afferent fibers. When single units were identified, receptive fields were mapped with a von Frey probe ( $1 \mathrm{~g})$, and baseline functional responses were systematically tested with mucosal stroking by curved von Frey filaments applied in a proximal-to-distal direction (10-1000 mg; each filament applied 10 times) and circumferential stretch applied with a claw, pulley, and cantilever system (1-5 g in $1 \mathrm{~g}$ increments; each weight applied for $20 \mathrm{~s}$, with a $20 \mathrm{~s}$ interstimulus interval). Serosal afferents were also tested for their response to von Frey probes applied perpendicular to the receptive field ( $70 \mathrm{mg}$ to $2 \mathrm{~g}$; each force applied once for $3 \mathrm{~s}$ ). Chemical activation and sensitization was only tested on fiber types that responded to stroking and/or stretch (i.e., muscular, mucosal, and muscular/mucosal). Immediately after baseline mechanical testing, a stainless steel cylindrical ring (height, $1 \mathrm{~cm}$; inner diameter, $4 \mathrm{~mm}$ ) was placed over the receptive field. Residual Krebs's solution was removed from within the ring before application of $150 \mu \mathrm{l}$ of chemical solution. After $1 \mathrm{~min}$, the chemical solution was withdrawn by pipette and the ring was removed. Repeat mechanical testing was performed immediately $(1 \mathrm{~min})$ and up to $30 \mathrm{~min}$ thereafter. Afferent fiber conduction velocity was measured at the end of some experiments by electrical stimulation of the receptive field with a bipolar electrode. A shortest-path approach was used to estimate the distance traveled by action potentials from the site of electrical stimulation to the recorded end of the nerve bundle, and the latency between the electrical stimulus 
and arrival of the action potential at the recording electrode was determined off-line from the experimental record.

Data and statistical analysis. Single units were discriminated off-line from the experimental record based on action potential waveform characteristics using Spike 2 software (Cambridge Electronic Design). Mucosal stroking stimulus-response functions were generated by averaging the number of action potentials produced during all 10 stroking tests for each filament intensity. Circumferential stretch stimulus-response functions were generated by averaging the total number of action potentials produced during the $20 \mathrm{~s}$ stimulation period for each intensity of stretch. von Frey probing stimulus-response functions were generated by averaging the mean spike rate over the $3 \mathrm{~s}$ application of each probe force. All data are expressed as mean \pm SEM. A $\chi^{2}$ analysis was performed to determine significant differences in the prevalence of each afferent type recorded from the pelvic nerves of TRPV1 knock-out and ASIC3 knockout mice. Differences in the percentage of afferents activated by inflammatory soup among all three mouse strains were tested for significance using individual $z$-tests for each fiber type. Two-way ANOVA and repeated-measures two-way ANOVA were used to identify statistical differences in chemical activation properties and stimulus-response functions, respectively, with Tukey's post hoc tests performed when appropriate. A level of $p<0.05$ was set for statistical significance.

Drugs. Bradykinin, serotonin $\mathrm{HCl}$, histamine $\mathrm{HCl}$, prostaglandin $\mathrm{E}_{2}$, capsaicin, amiloride $\mathrm{HCl}$, and capsazepine were all purchased from Sigma (St. Louis, MO). Aliquots $(20 \mu \mathrm{l})$ of inflammatory soup were prepared by combining bradykinin, serotonin, and histamine dissolved in distilled water with prostaglandin $\mathrm{E}_{2}$ dissolved in dimethylsulfoxide (DMSO) and stored at $-20^{\circ} \mathrm{C}$. The aliquots were diluted to final concentration ( $5 \mu \mathrm{M})$ in either neutral (7.4) or acidified (6.0) Krebs' solution on the day of the experiment. The acidity of the Krebs' solution was adjusted to the appropriate $\mathrm{pH}$ using $12 \mathrm{~N}$ hydrochloric acid. Capsaicin, amiloride, and capsazepine were dissolved in $10 \mu \mathrm{l}$ aliquots of DMSO and stored at $-20^{\circ} \mathrm{C}$ until dilution to final concentration $(3,500$, and $500 \mu \mathrm{M}$, respectively) in neutral Krebs's solution for experiments. Capsaicin was applied at the conclusion of each experiment to avoid any potential desensitization of afferent fibers.

\section{Results}

Deletion of TRPV1 or ASIC3 impairs visceral nociception in mice

Visceral nociception was assessed in control, TRPV1 knock-out, and ASIC3 knock-out mice by measuring the VMR to phasic CRD with an inflatable balloon (Fig. 1). Increasing distension pressures evoked graded responses in all three mouse strains. However, both TRPV1 and ASIC3 knock-out mice were significantly less sensitive to distension than control mice (repeated measures two-way ANOVA; $F=$ 8.3; $p<0.001)$. This effect was significant at all pressures tested (Tukey's post hoc test; $15 \mathrm{mmHg}, p<0.05 ; 30 \mathrm{mmHg}, p<0.01 ; 45$ $\mathrm{mmHg}, p<0.01 ; 60 \mathrm{mmHg}, p<0.001)$.

\section{The pelvic nerves of TRPV1 and ASIC3 knock-out mice contain a full complement of mechanosensitive colon afferent fiber types}

To identify the contributions of TRPV1 and ASIC3 to peripheral mechanosensation in the colon, single-fiber electrophysiology was performed using an in vitro colon-pelvic nerve preparation. Afferent fiber types were identified according a previously described classification scheme (Brierley et al., 2004) based on their sensitivity to two types of mechanical stimuli: fine mucosal stroking (10 mg) and circumferential stretch (Fig. 2, top). These stimuli reflect in the in vitro preparation the forces produced by colonic contents in vivo (specifically, longitudinal transport and organ distension). Muscular afferents were defined by their sensitivity to stretch but not fine stroking, and mucosal afferents were defined by their sensitivity to fine stroking but not stretch. Muscular/mucosal afferents responded to both types of mechan-
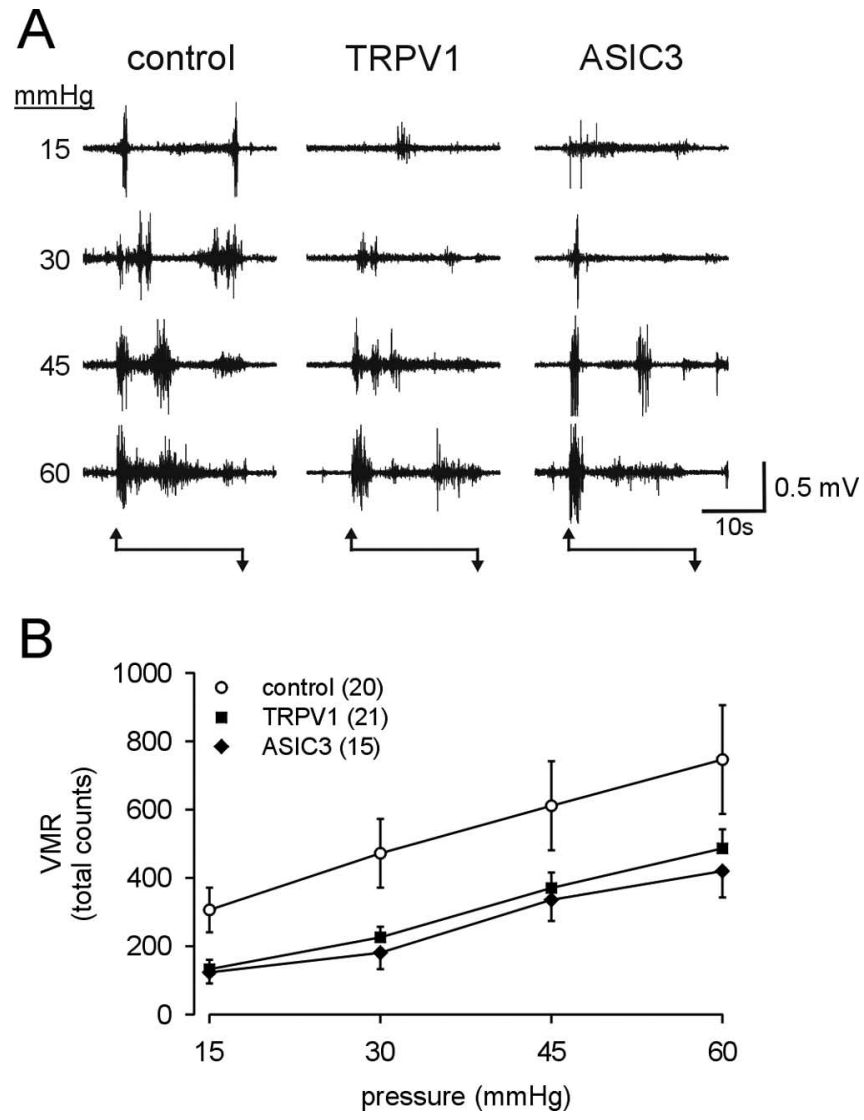

Figure 1. Impaired visceral nociception in TRPV1 and ASIC3 knock-out mice. The VMR to CRD was recorded in control (C57BL/6), TRPV1 knock-out, and ASIC3 knock-out mice by electromyographic electrodes implanted in the abdominal musculature. $A$, Raw electromyographic recordings from control (left), TRPV1 knock-out (middle), and ASIC3 knock-out (right) mice. Vertical calibration bar, $0.5 \mathrm{mV}$. B, Plot of CRD stimulus-response functions for each mouse strain. Graded responses to phasic distension with increasing balloon inflation pressures were obtained in all three strains. Responses of TRPV1 and ASIC3 knock-out mice were significantly lower than control mice $(p<0.001)$. This effect was significant at all distension pressures tested ( $p<0.05$ in all cases). The numbers of animals tested for each mouse strain are listed in parentheses.

ical stimuli, whereas serosal afferents responded to neither; serosal afferents could be activated by direct von Frey probing. Similar percentages of each fiber type were recorded from TRPV1 and ASIC3 knock-out mice (Fig. 2, bottom) and approximate percentages reported previously for colon afferent fibers in the pelvic nerve of C57BL/6 mice (Brierley et al., 2004).

\section{Functional mapping of mechanosensitive afferent fiber receptive fields in the mouse colon}

Receptive fields were mapped by von Frey probe at the start of each experiment (Table 1). Most fibers possessed a single receptive field, but multiple fields were found sporadically in all three mouse strains: two receptive fields were observed in seven fibers (one muscular, three mucosal, one muscular/mucosal, and two serosal), and three receptive fields were found in three muscular afferents. Receptive fields ranged in size from 1 to $9 \mathrm{~mm}^{2}$, often with larger longitudinal dimensions (i.e., long, slender fields aligned with the longitudinal muscle layer of the colon) and varied significantly based on fiber type and mouse strain (two-way ANOVA; afferent type, $F=4.2, p=0.007$; mouse strain, $F=4.1$, $p=0.018)$. Muscular/mucosal afferent receptive fields were significantly larger than those of serosal afferents (Tukey's post hoc 


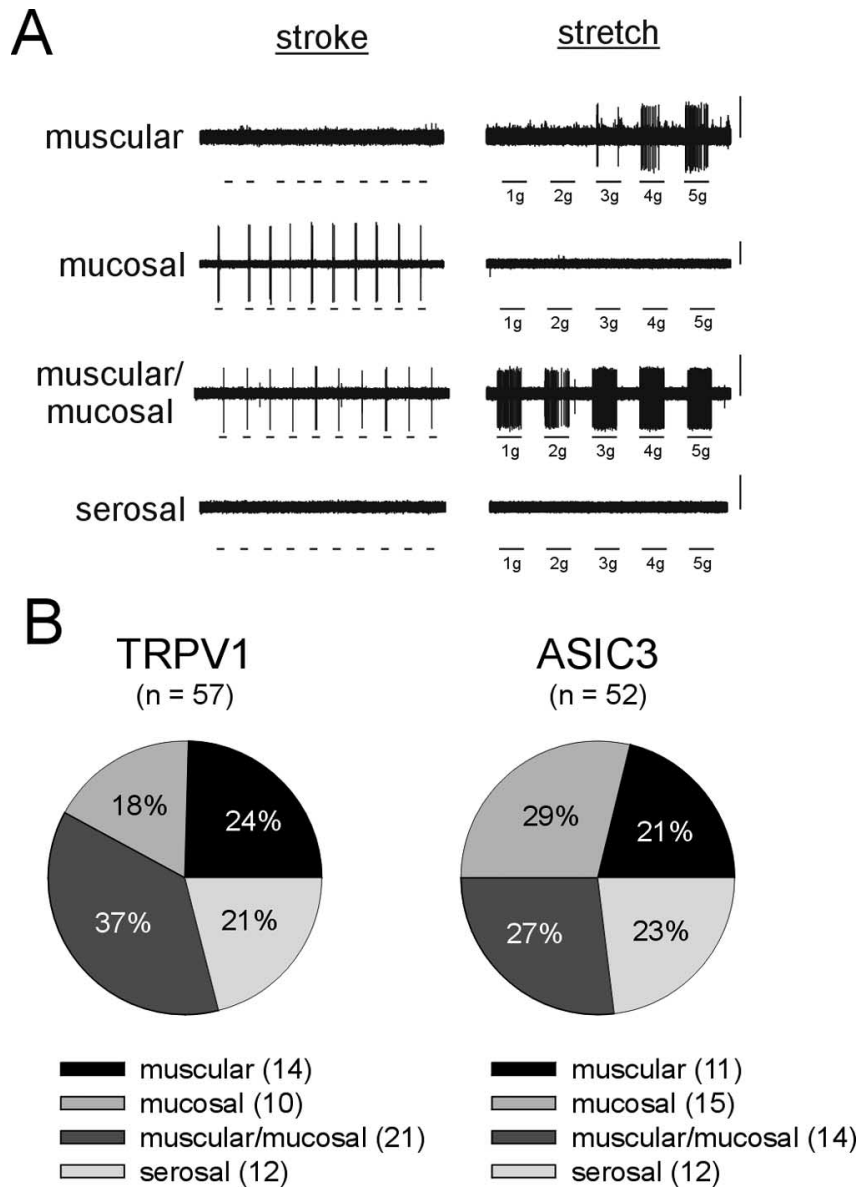

Figure 2. Colon afferent fiber types recorded from the pelvic nerves of TRPV1 knock-out and ASIC3 knock-out mice. $\boldsymbol{A}$, Four fiber types were identified in both knock-out mouse strains: muscular, mucosal, muscular/mucosal, and serosal. Muscular afferents were defined by their sensitivity to circumferential stretch and insensitivity to fine mucosal stroking ( $10 \mathrm{mg}$; lines beneath each record). Mucosal afferents possessed the opposite phenotype: sensitivity to fine stroking and insensitivity to stretch. Muscular/mucosal afferents were sensitive to both fine stroking and stretch. Serosal afferents were insensitive to fine stroking and stretch; these afferents could be mechanically activated by direct von Frey probing $(1 \mathrm{~g})$. Vertical calibration bars, $100 \mu$ V. B, Similar percentages of each fiber type were recorded from TRPV1 and ASIC3 knockout mice ( $n$ values are shown in parentheses).

test, $p=0.003$ ), and receptive fields of mucosal afferents in both TRPV1 and ASIC3 knock-out mice were significantly smaller than those in control mice (Tukey's post hoc test; TRPV1 knock-out, $p<0.001$; ASIC3 knock-out, $p=0.012$ ). In general, one punctate "hot spot" was identified within the receptive field from which von Frey probing readily produced activation (Fig. 3). These hotspots were concentrated in the distal $4 \mathrm{~cm}$ of the colon, including the rectum and anal canal, and distributed throughout the anteroposterior axis. No obvious differences were noted in the distribution of afferent receptive fields among control, TRPV1 knock-out, and ASIC3 knockout mice, nor were there obvious differences in the distribution of fibers activated by and those not activated by chemical inflammatory mediators. Serosal afferent receptive fields recorded in TRPV1 and ASIC3 knock-out mice were similarly distributed (data not shown).

\section{Chemical confirmation of TRPV1 deletion in TRPV1 \\ knock-out mice}

To confirm the functional deletion of TRPV1 in the TRPV1 knock-out mice, capsaicin ( $3 \mu \mathrm{M}, 2 \mathrm{~min})$ was applied to afferent fiber receptive fields in control and TRPV1 and ASIC3 knock-out mice at the end of some experiments. Whereas capsaicin excited afferent fibers of all types in similar proportions in control and ASIC3 knock-out mice, no afferent fibers tested in TRPV1 knock-out mice were activated by application of capsaicin to the receptive field (Table 1 ).

\section{Functional properties of mechanosensitive colon afferent} fibers in TRPV1 and ASIC3 knock-out mice

Baseline mechanosensitivity testing with graded mucosal stroking and circumferential stretch was performed in all four afferent fiber types. Mucosal stroking with calibrated von Frey filaments produced graded responses in every fiber type, but mucosal and muscular/mucosal afferents were, by definition, able to detect the lowest filament strength tested (10 mg) (Fig. 4). Although muscular/mucosal afferents in ASIC3 knock-out mice tended to be less sensitive than those in control and TRPV1 knock-out mice, no significant differences were detected in afferent fiber responses to mucosal stroking. Graded responses to circumferential stretch were also obtained in muscular and muscular/mucosal afferents in all three mouse strains (Fig. 5). Muscular afferents in TRPV1 knock-out mice tended to be more sensitive than those in control or ASIC3 knock-out mice, but this difference was not significant. In contrast, muscular/mucosal afferents in both TRPV1 and ASIC3 knock-out mice were significantly less sensitive to stretch than control afferent fibers (Fig. 5A, $B$, right) (repeated-measures two-way ANOVA; $F=6.0 ; p=0.005$ ). Stretch-evoked responses consisted of an initial dynamic phase followed by adaptation to sustained stimulus application (Fig. $5 C$ ). The reduced stretch sensitivity of muscular/mucosal afferents in TRPV1 and ASIC3 knock-out mice consisted of a decrease in both the dynamic and adaptation phases (Fig. $5 C$, right). In control mice, pharmacologic blockade of TRPV1 with capsazepine ( $500 \mu \mathrm{M}, 5 \mathrm{~min}$ ) produced a similar and significant decrease in stretch-evoked responses of muscular/mucosal afferents (Fig. 6A) (repeated-measures two-way ANOVA; $F=5.9 ; p=$ $0.02)$. Amiloride $(500 \mu \mathrm{M}, 5 \mathrm{~min})$, a nonselective ASIC antagonist, was unable to significantly affect the stretch sensitivity of muscular/mucosal afferents in control mice (Fig. $6 \mathrm{~B}$ ).

The basal mechanosensitivity of serosal afferents was tested in TRPV1 and ASIC3 knock-out mice for comparison with previously published functional properties of this fiber type in wildtype control C57BL/6 mice (Brierley et al., 2004). Serosal afferents in both knock-out mouse strains generated graded responses to von Frey probing that were not significantly different between knock-out mouse strains (data not shown) (repeated-measures two-way ANOVA; $F=0.48 ; p=0.50)$ and are similar to those reported previously for serosal afferents in the pelvic nerve of C57BL/6 mice (Brierley et al., 2004). The physiological significance of serosal afferent sensitivity to von Frey probing is unclear; therefore, this fiber type was excluded from additional testing.

\section{Effects of TRPV1 and ASIC3 gene deletion on the activation} and sensitization of colon afferent fibers by acidic inflammatory soup

The chemosensitivity of colon afferent fibers in the mouse was tested by receptive field application of an acidic ( $\mathrm{pH}$ 6.0) inflammatory soup. The majority of afferent fibers in control, TRPV1 knock-out, and ASIC3 knock-out mice were activated by acidic inflammatory soup, generating a sustained burst of action potentials that gradually waned to background activity after removal of the chemical stimulus (Fig. 7A). Similar percentages of each fiber 
Table 1. Comparison of structural properties and capsaicin sensitivity among mechanosensitive colon afferent fibers in control (C57BL/6), TRPV1 knock-out, and ASIC3 knock-out mice

\begin{tabular}{|c|c|c|c|c|c|c|c|c|c|c|c|c|}
\hline \multirow[b]{2}{*}{ Strain } & \multicolumn{3}{|l|}{ Muscular } & \multicolumn{3}{|l|}{ Mucosal } & \multicolumn{3}{|c|}{ Muscular/mucosal } & \multicolumn{3}{|l|}{ Serosal } \\
\hline & $\mathrm{rf}\left(\mathrm{mm}^{2}\right)$ & $\mathrm{cv}(\mathrm{m} / \mathrm{s})$ & cap + & rf $\left(\mathrm{mm}^{2}\right)$ & $\mathrm{cv}(\mathrm{m} / \mathrm{s})$ & cap + & If $\left(\mathrm{mm}^{2}\right)$ & $\mathrm{cv}(\mathrm{m} / \mathrm{s})$ & cap + & $\mathrm{rf}\left(\mathrm{mm}^{2}\right)$ & $\mathrm{cv}(\mathrm{m} / \mathrm{s})$ & cap + \\
\hline Control & $3.0 \pm 0.3$ & $0.70 \pm 0.05$ & $6 / 10$ & $4.0 \pm 0.3$ & $0.74 \pm 0.04$ & $3 / 6$ & $3.4 \pm 0.3$ & $0.76 \pm 0.04$ & 8/1 & $2.7 \pm 0.8$ & $0.69 \pm 0.09$ & $2 / 9$ \\
\hline TRPV1 & $3.3 \pm 0.4$ & $0.73 \pm 0.05$ & & $1.6^{*} \pm 0.4$ & $0.60 \pm 0.06$ & & $3.4 \pm 0.3$ & $0.70 \pm 0.04$ & ort & $1.4 \pm 0.4$ & $0.58 \pm 0.04$ & $2 / 7$ \\
\hline (n) & & & $0 / 8$ & & & $0 / 8$ & & & $0 / 9$ & & & $0 / 6$ \\
\hline ASIC3 & $2.5 \pm 0.4$ & $0.37 \pm 0.12$ & & $2.6^{*} \pm 0.4$ & $0.71 \pm 0.05$ & & $3.0 \pm 0.4$ & $0.75 \pm 0.07$ & & $1.7 \pm 0.4$ & $0.55 \pm 0.06$ & \\
\hline (n) & (11) & (3) & $3 / 8$ & $(15)$ & (8) & $4 / 10$ & (14) & (5) & $1 / 8$ & (12) & (4) & $2 / 8$ \\
\hline
\end{tabular}

All afferent fibers were determined to be C-fibers, with conduction velocities (cv) $<2 \mathrm{~m} / \mathrm{s}$. Receptive field area (rf) varied significantly based on fiber type and mouse strain (two-way ANOVA; afferent type, $p=0.007$; strain, $p=0.018$ ). Posthoc testing revealed that receptive fields of muscular/mucosal afferents were significantly larger than those of serosal afferents $(p=0.003)$ and that mucosal afferent receptive fields in TRPV1 knock-out and ASIC 3 knock-out mice were significantly smaller than those in control mice ${ }^{*} p<0.05$ for both analyses). The capsaicin (cap) sensitivity of pelvic nerve colon afferent fibers was tested by application of capsaicin ( $3 \mu \mathrm{m}, 2$ min) to receptive fields at the end of the experiment to avoid potential desensitizing effects of the drug. A proportion of all four afferent fiber types in control and ASIC 3 knock-out mice responded to capsaicin, although it did not activate any afferent fiber tested in TRPV1 knock-out mice. Data are expressed as mean \pm SD.

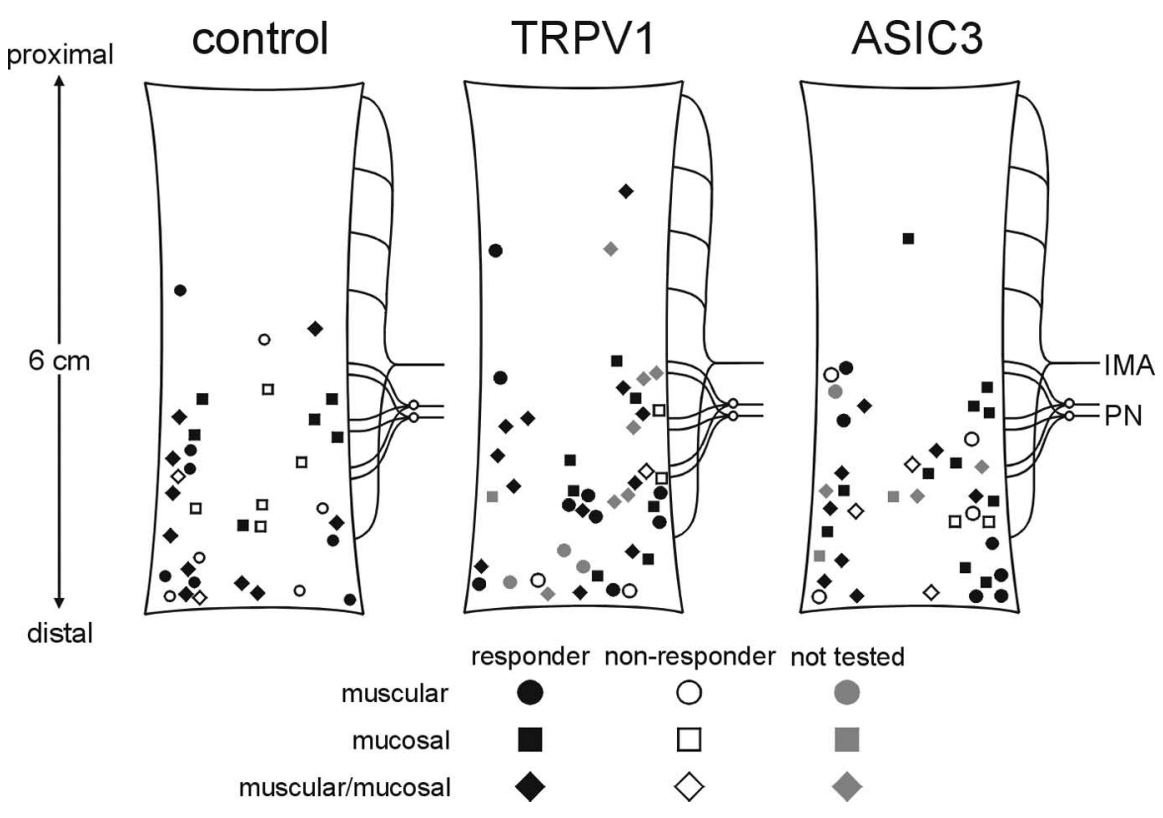

Figure 3. Comparison of muscular, mucosal, and muscular/mucosal afferent receptive field distributions among control (C57BL/6), TRPV1 knock-out, and ASIC3 knock-out mouse strains. Receptive fields of colon afferent fibers in all three mouse strains were distributed throughout the distal $4 \mathrm{~cm}$ of the colon, including the rectum and anal canal. No obvious differences were noted in the distribution of afferent fibers activated by acidic inflammatory soup (responders; black symbols) and those that were not activated (nonresponders; white symbols); the location of afferent fibers not tested with acidic inflammatory soup are also shown (gray symbols). IMA, Inferior mesenteric artery; PN, pelvic nerves.

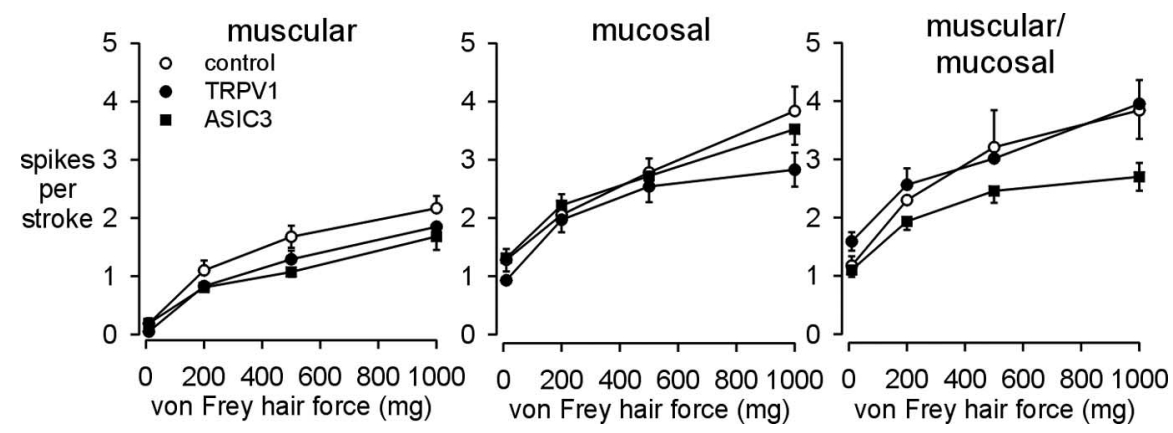

Figure 4. Colon afferent fiber sensitivity to mucosal stroking was unaffected by deletion of TRPV1 or ASIC3. Graded responses to mucosal stroking with von Frey filaments were obtained in all three mouse strains. Notably, mucosal and muscular/mucosal afferents responded to stroking with the lowest intensity filament $(10 \mathrm{mg})$ that was only of sufficient strength to disturb the superficial tissue layer. Mucosal stroking stimulus-response functions of muscular, mucosal, and muscular/mucosal afferents in control (C57BL/6), TRPV1 knock-out, and ASIC3 knock-out mice were not significantly different. type were activated by acidic inflammatory soup among the three mouse strains (Fig. $7 B)$. The latency to onset of activation, the duration of activation, and maximum instantaneous firing frequency achieved during activation were measured to compare chemical activation patterns among fiber types and mouse strains (Fig. 7C). TRPV1 or ASIC3 deletion had no significant effect on the afferent fiber activation patterns compared with control mice.

Changes in afferent fiber mechanosensitivity produced by acidic inflammatory soup were assessed by mechanical testing immediately after and at regular intervals after chemical application. In control mice, afferent fiber sensitivity to mucosal stroking was unaffected (data not shown) (repeated-measures two-way ANOVA; muscular, $F=0.42, p=0.53$; mucosal, $F=$ $1.8, p=0.20$; muscular/mucosal, $F=0.42$, $p=0.53$ ), but circumferential stretchevoked responses of both muscular and muscular/mucosal afferents were significantly enhanced by chemical exposure (Fig. $8 A$ ) (repeated-measures two-way ANOVA; muscular, $F=6.5, p=0.03$; muscular/mucosal, $F=19.7, p<0.001)$. Sensitization was specific to the combination of acidic $\mathrm{pH}$ and inflammatory soup; neither acid alone $(\mathrm{pH}$ 6.0) nor neutral ( $\mathrm{pH} 7.4$ ) inflammatory soup sensitized stretch-evoked responses of either fiber type (Fig. $8 \mathrm{~B}$ ).

The ability of acidic inflammatory soup to enhance afferent fiber sensitivity to circumferential stretch was tested in TRPV1 and ASIC3 knock-out mice. Like those in control mice, muscular/mucosal afferents in TRPV1 knock-out mice were also sensitized by acidic inflammatory soup (Fig. $8 C$ ) (repeated-measures two-way ANOVA; $F=$ 22.1; $p<0.001)$; however, no sensitization was observed in muscular afferents in these knock-out mice. In contrast, neither muscular nor muscular/mucosal afferents were sensitized by acidic inflammatory soup in ASIC3 knock-out mice (Fig. 8D). 
A
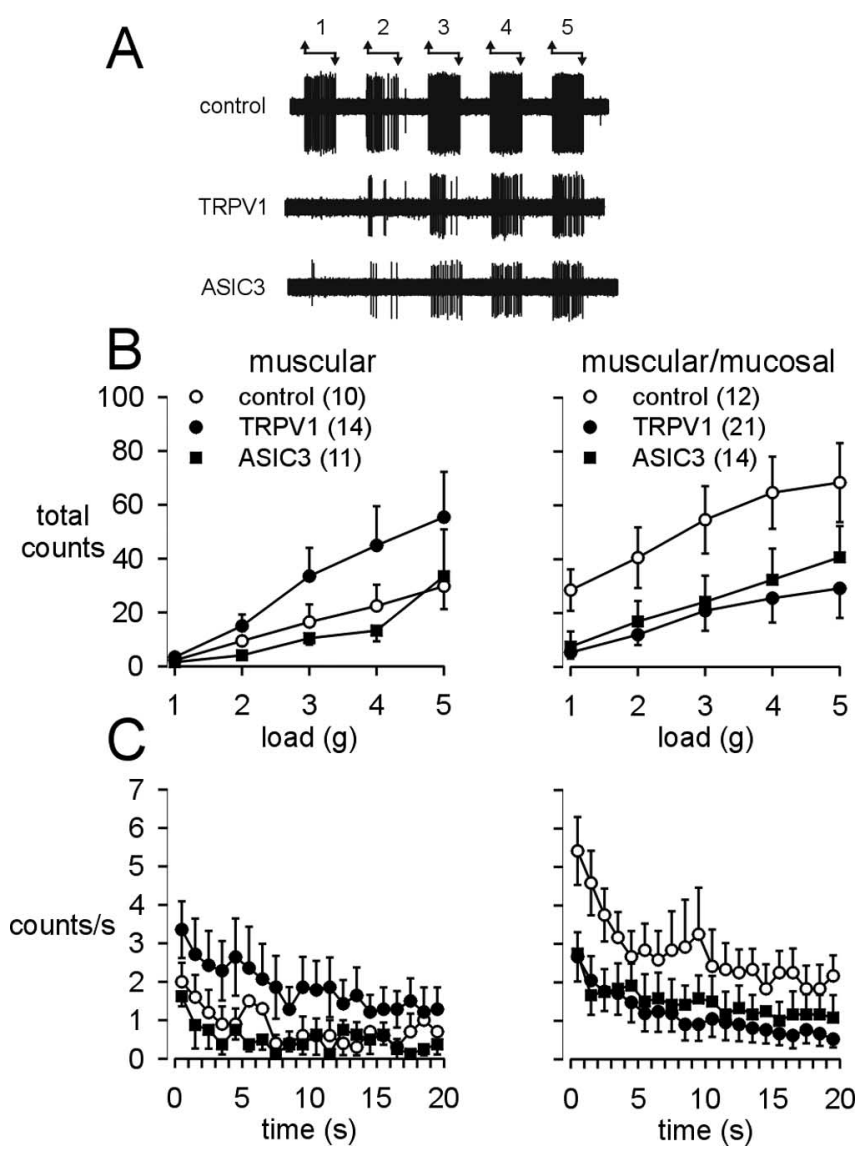

Figure 5. Impaired circumferential stretch sensitivity of muscular/mucosal afferent fibers in TRPV1 and ASIC3 knock-out mice. $\boldsymbol{A}$, Representative traces of muscular/mucosal afferents of control (C57BL/6), TRPV1 knock-out, and ASIC3 knock-out mice. $\boldsymbol{B}$, Circumferential stretch stimulus-response functions of muscular (left) and muscular/mucosal (right) afferents. Muscular/mucosal afferents in both knock-out strains were significantly less sensitive than afferent fibers in control mice ( $p=0.005$ ); significant differences were detected in afferent responses to loads $\geq 3 \mathrm{~g}(p<0.05)$. C, Adaptation of muscular (left) and muscular/mucosal (right) afferents to a $20 \mathrm{~s}$ application of a $5 \mathrm{~g}$ load. Muscular and muscular/mucosal afferents in all mouse strains adapted throughout the duration of the stimulus period. Muscular/mucosal afferents in control mice responded at higher levels than those in TRPV1 or ASIC3 knock-out mice during both the initial dynamic phase of the stretch response and the subsequent adaptation phase.
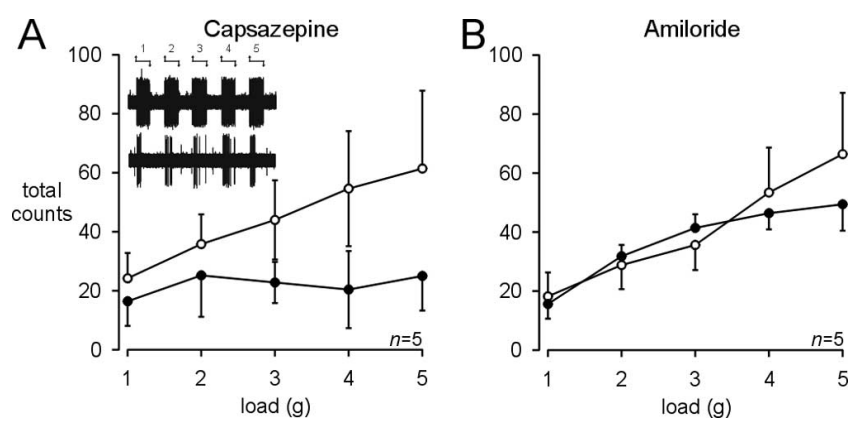

Figure 6. Pharmacological inhibition of colon afferent fiber sensitivity to circumferential stretch. Effect of capsazepine, a TRPV1 receptor antagonist, and amiloride, a nonselective ASIC antagonist, on the stretch-evoked responses of muscular/mucosal afferents in control (C57BL/6) mice. $A$, Exposure of muscular/mucosal afferent receptive fields to capsazepine (500 $\mu \mathrm{M}, 5 \mathrm{~min}$ ) resulted in a significant decrease in stretch sensitivity $(p=0.02)$; stretch-evoked responses were attenuated up to $30 \mathrm{~min}$ after capsazepine was removed (data not shown). Inset, Representative traces of stretch responses of a muscular/mucosal afferent before (top) and after (bottom) application of capsazepine. $\boldsymbol{B}$, Amiloride (500 $\mu \mathrm{m}, 5 \mathrm{~min}$ ) had no significant effect on the stretch sensitivity of muscular/mucosal afferents in control mice.

\section{Discussion}

These experiments were designed to test the contributions of two putative mechanosensors, TRPV1 and ASIC3, to visceral mechanosensation and hypersensitivity. In most respects, mechanosensitive colon afferent fibers in the knock-out mice were indistinguishable from those in control mice. Each knock-out strain possessed a full repertoire of fiber types, and their sensitivity to mucosal stroking was intact. However, the sensitivity of muscular/mucosal afferents to circumferential stretch was significantly reduced in both knock-out strains compared with controls. Muscular/mucosal afferents are the predominant stretch-sensitive fiber type in the mouse colon and encode stretch intensity into the noxious range (Brierley et al., 2004). The functional importance of a reduction in afferent fiber sensitivity to colonic stretch is underscored by the parallel reduction in behavioral sensitivity to colorectal distension observed in TRPV1 and ASIC3 knock-out mice. This is the first report, to our knowledge, of visceral mechanosensory deficits at a behavioral level in either knock-out mouse strain. Moreover, these results demonstrate that TRPV1 and ASIC3 contribute to the perception of noxious mechanical stimuli in the colon by specifically enabling the peripheral detection of circumferential stretch of the colonic wall and not other types of mechanical stimuli.

Primary afferent fibers from the colon detect a variety of mechanical stimuli that generate intrinsic reflexes regulating gastrointestinal function and extrinsic reflexes that produce pain. Organ distension is the primary physical stimulus capable of producing reports of pain in humans (Ritchie, 1973) and pseudaffective responses in animals (Ness and Gebhart, 1988). Although mechanosensitive structures have not been described in the small or large intestine, circumferential stretch of the esophagus, stomach, and rectum is thought to be detected by intraganglionic laminar endings (IGLEs) (Lynn et al., 2003; Zagorodnyuk and Brooks, 2000; Zagorodnyuk et al., 2001). Indeed, Zagorodnyuk et al. (2003) recently reported that esophageal IGLEs directly transduce mechanical stimuli. The identity of the molecules that confer mechanosensitivity to these structures is unknown, but we provide evidence to suggest that TRPV1 and ASIC3 may contribute to this function.

TRPV1, known for its thermosensing abilities (Caterina et al., 1997), has previously been implicated in visceral mechanosensation. Deletion of TRPV1 impairs afferent fiber detection of mechanical stimuli in the jejunum (Rong et al., 2004) and bladder (Birder et al., 2002). The diminished stretch-evoked responses of colon afferent fibers in TRPV1 knock-out mice lend additional support to the hypothesis that TRPV1 is an important mediator or modulator of mechanosensitivity in the viscera. This contrasts with reports of normal cutaneous mechanosensitivity, in terms of both animal behavior and afferent fiber function in TRPV1 knock-out mice (Caterina et al., 2000) and together indicate that TRPV1 may have different functions in different body tissues. Application of capsazepine, a TRPV1 antagonist, to pelvic nerve afferent fiber receptive fields in control mice also attenuated stretch-evoked responses. This finding should be interpreted with caution, however, because the concentration necessary for an effect in our preparation was higher than used by other groups in different in vitro preparations (Rong et al., 2004).

Members of the ASIC family, including ASIC3, have been proposed to serve a mechanosensory function in the periphery. Cutaneous afferent fibers of ASIC2 and ASIC3 knock-out mice possess altered mechanical response properties that are hypothesized to be important for the detection of touch (Price et al., 
A
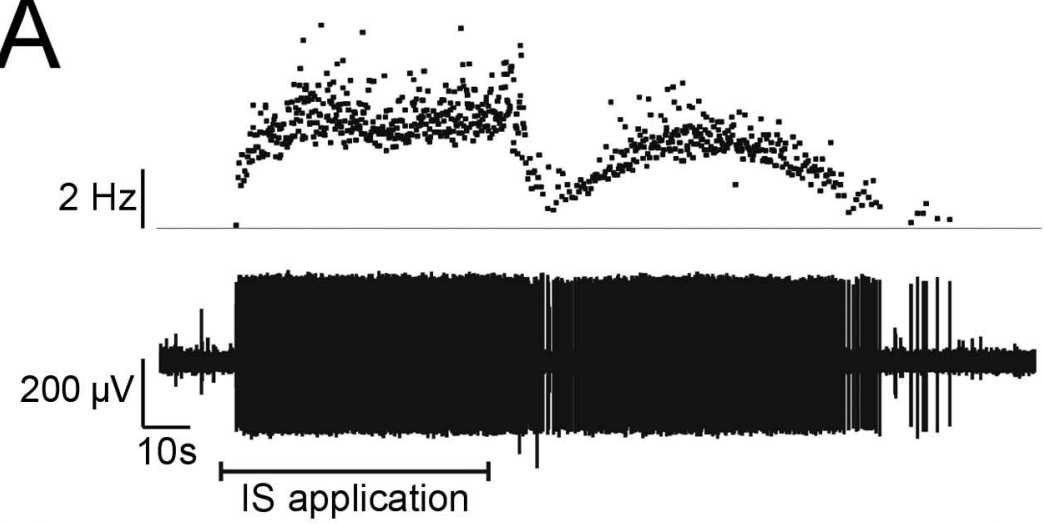

B

muscular

mucosal
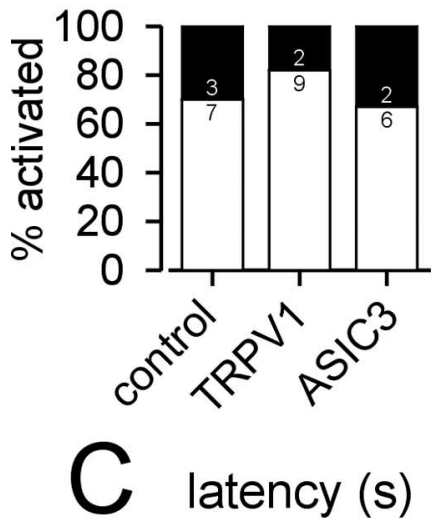

latency (s)
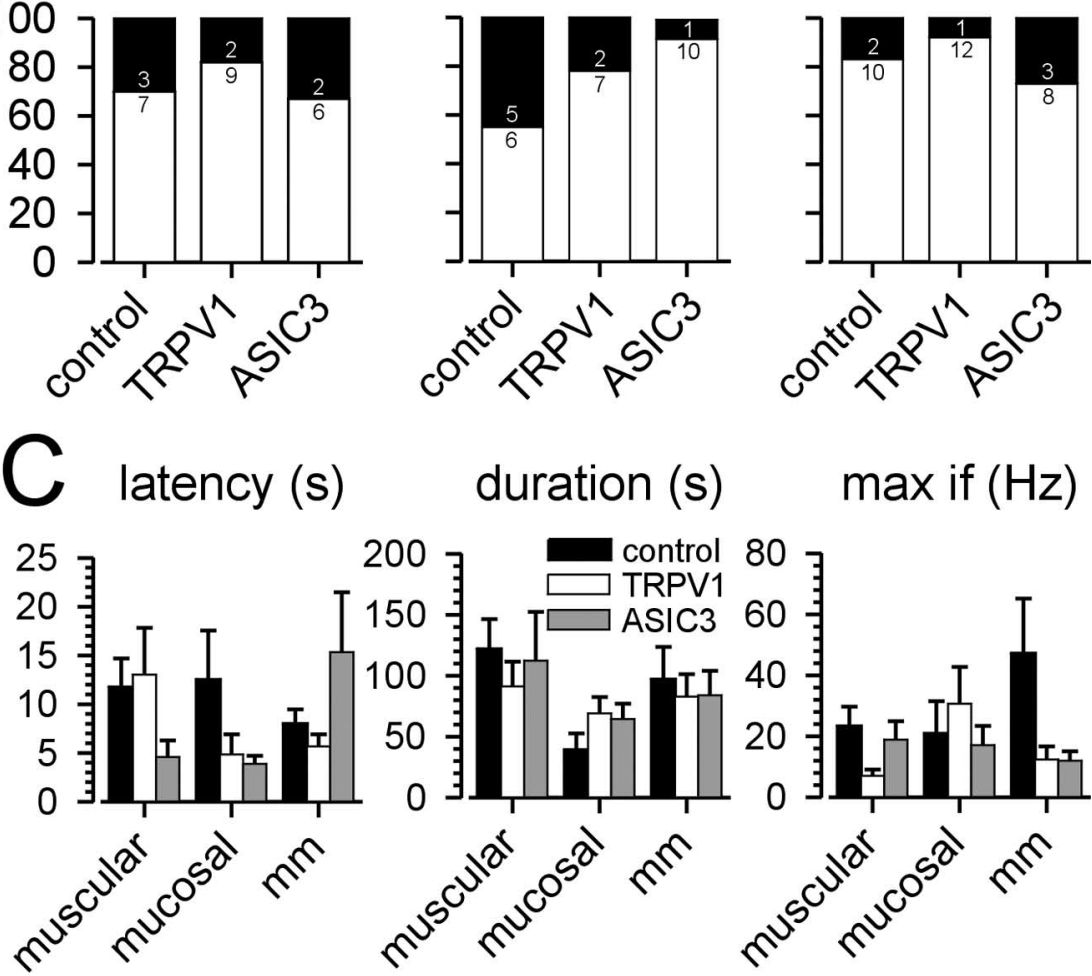

Figure 7. Deletion of TRPV1 or ASIC3 did not affect colon afferent fiber chemosensitivity. $\boldsymbol{A}$, Representative trace (bottom) and plot of maximum instantaneous firing frequency (top) of a muscular/mucosal afferent fiber activated by a 1 min exposure to acidic (pH 6.0) inflammatory soup (IS). Chemical activation was characterized by an increase in action potential firing above background (spontaneous activity was absent in all fibers) that followed the chemical application at a variable latency and extended beyond the application period for a variable duration. $\boldsymbol{B}$, The majority of afferent fibers in control (C57BL/6), TRPV1 knock-out, and ASIC3 knock-out mice were activated by acidic inflammatory soup. Depicted are the percentages and numbers of fibers activated (white bars, black numbers) and not activated (black bars, white numbers) for each fiber type in the three mouse strains. No significant differences were detected in the number of afferents activated by chemical exposure. C, Deletion of TRPV1 or ASIC3 did not affect afferent fiber activation properties. No significant differences were observed among the three mouse strains in the latency to activation (left), duration of activation (middle), or maximum instantaneous frequency (max if; right) achieved during activation. $\mathrm{mm}$, Muscular/mucosal.

2000, 2001). In ASIC3 knock-out mice, these effects are varied, with increased sensitivity of cutaneous, low-threshold mechanoreceptors but decreased sensitivity of A-fiber mechanonociceptors (Price et al., 2001). In the gut, Page et al. (2005) demonstrated mechanosensory deficits in stomach and colon afferent fibers found in the vagus and splanchnic nerve, respectively, of ASIC3 knock-out mice. The decreased sensitivity of pelvic nerve afferent fibers in ASIC3 knock-outs that we observed is similar to

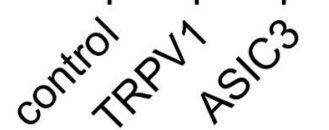

muscular/ mucosal

the deficits of cutaneous A-fiber mechanonociceptors and gastrointestinal vagus and splanchnic nerve afferents. Interestingly, Page et al. $(2004,2005)$ describe a hypersensitive and mixed hypersensitive and hyposensitive phenotype of colon afferent fibers in ASIC1 and ASIC2 knockout mice, respectively. Therefore, different ASIC subunits may exert opposing effects on mechanosensation in the viscera: inhibition by ASIC1 and facilitation by ASIC3. A role for ASIC3 in colon afferent fiber function was not verified with amiloride in the present experiments; however, this drug is a relatively nonselective ASIC antagonist and unable to completely block ASIC3 currents even at high doses (Waldmann et al., 1997).

Arguing against the hypothesis that ASIC3 acts as a peripheral mechanosensor is evidence that, in cell culture, mechanical deformation of sensory neurons from ASIC3 knock-out mice elicits ionic currents no different from those obtained in wild-type control neurons (Drew et al., 2004). Interpretation of these results is challenging because cultured neurons lack accessory components that participate in mechanotransduction. In addition, sensory neurons from several spinal levels were pooled in this study without retrograde tracing from the tissue of origin, thereby preventing detection of effects of ASIC3 deletion that may be specific to different tissues and afferent fiber types. Additional studies, comparing neuronal populations with known innervation territories and functional properties in a physiologic context, are necessary to determine the precise role of ASIC3 in the detection of mechanical stimuli in the periphery.

The precise mechanisms by which TRPV1 and ASIC3 contribute to the activation of colon afferent fibers by mechanical stimuli remains to be determined. Two possibilities have been proposed (Welsh et al., 2002). They may be directly activated by mechanical forces via tethering molecules to the extracellular and/or intracellular environment, as has been described for the degenerin family of proteins, relatives of the ASICs found in Drosophila (Welsh et al., 2002). Alternatively, they may be indirectly activated by diffusible secondary messengers released from other nearby cells, analogous to the participation of purinergic receptors in visceral mechanosensation (Wynn et al., 2003). Future experiments will elucidate which of these (or other) mechanisms is responsible.

In addition to their contributions to basal mechanosensitivity, TRPV1 and ASIC3 were required for the sensitization, but not activation, of colon afferent fibers by acidic ( $\mathrm{pH}$ 6.0) inflammatory soup. In control mice, receptive field application of acidic 

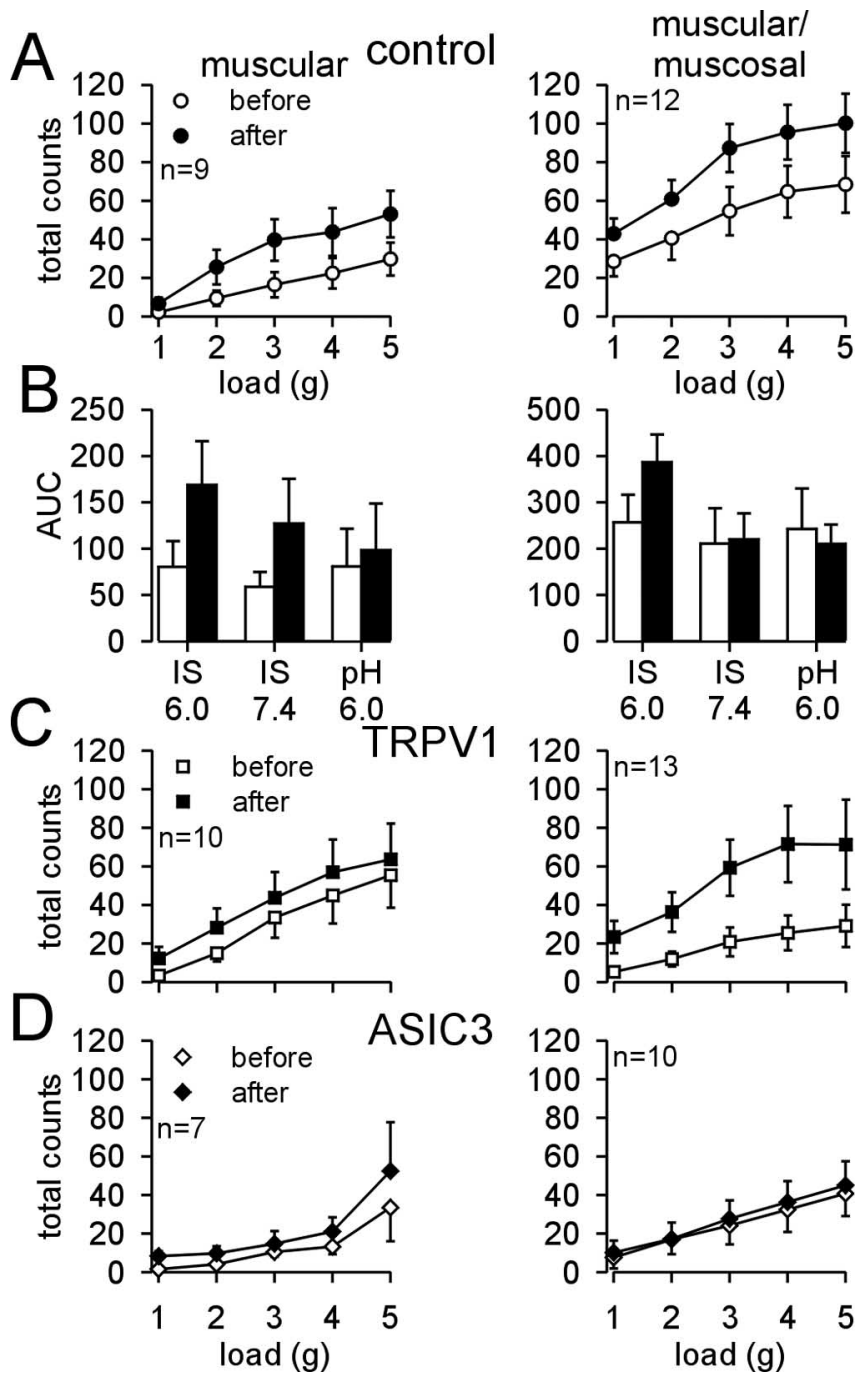

Figure 8. TRPV1 and ASIC3 are differentially required for the sensitization of mouse colon afferent fibers to circumferential stretch produced by acidic ( $\mathrm{pH}$ 6.0) inflammatory soup. $\boldsymbol{A}$, Chemical exposure resulted in a significant increase in the sensitivity of muscular and muscular/ mucosal afferents to circumferential stretch in control (C57BL/6) mice (muscular, $p=0.03$; muscular/mucosal, $p<0.001)$. Differences were significant in muscular afferents for loads $\geq 3$ $\mathrm{g}(p<0.05)$ and in muscular/mucosal afferents for loads $\geq 2 \mathrm{~g}(p<0.01)$. $\boldsymbol{B}$, Area under the curve (AUC) analysis of stretch stimulus-response functions before (unfilled bars) and after (filled bars) chemical treatment (IS 6.0, acidic inflammatory soup; IS 7.4, neutral inflammatory soup; pH 6.0, acid alone) of muscular and muscular/mucosal afferents in control mice. C, Significant sensitization was only observed in muscular/mucosal afferents of TRPV1 knock-out mice ( $p<0.001$ ); no significant difference was observed in the stretch responses of muscular afferents before and after acidic inflammatory soup. $D$, Neither muscular nor muscular/mucosal afferents in ASIC3 knock-out mice were significantly sensitized to stretch after chemical exposure.

inflammatory soup excited a majority of fibers, producing an increase in spontaneous activity from background levels that waned after washout. Polymodality has been demonstrated previously in visceral afferent fibers of other animal species, but no study we are aware of has demonstrated this trait in afferent fibers in the pelvic nerve of the mouse. This provides an important point of commonality between the mouse and other species that validates the use of the mouse to study colon afferent fiber biology. Deletion of TRPV1 or ASIC3 had no effect on afferent fiber sensitivity to the chemical ingredients of the inflammatory soup; like those in control mice, the majority of fibers in both knock-out strains were activated by acidic inflammatory soup, suggesting that neither gene product is responsible for chemical activation.

The sensitization of afferent fiber function by acidic inflammatory soup was very specific, in terms of both the type of chemical stimulus required to produce sensitization and the type of mechanical stimulus to which responses were sensitized. Neutral inflammatory soup, despite its ability to produce excitation, did not significantly affect responses of any fiber type to either mucosal stroking or circumferential stretch. Application of acid alone was similarly ineffective. However, when combined, a significant increase in response to circumferential stretch was observed in both types of stretch-sensitive fiber. These results demonstrate a synergistic interaction of low $\mathrm{pH}$ with the chemical components of inflammatory soup to selectively enhance the sensitivity of afferent fibers to colonic stretch. Each of the components of the acidic inflammatory soup has the potential to act on distinct or partially overlapping groups of receptors and, consequently, to produce individualized and interacting effects on afferent function. They were applied in combination based on the premise expressed by Handwerker and Reeh (1991) that the inflammatory soup, although surely not representative of all chemical mediators elaborated during tissue inflammation and applied in supraphysiologic concentrations, would act in concert under disease conditions in vivo to affect sensory neuron function. The present results suggest that chemical mediators released during tissue insult not only activate but also sensitize afferent fibers in the colon to mechanical stimuli.

Chemical sensitization of stretch-sensitive afferent fibers was differentially affected in the two knock-out strains. In TRPV1 knock-out mice, muscular afferents did not sensitize after exposure to acidic inflammatory soup, whereas sensitization was preserved in muscular/mucosal afferents. In contrast, neither fiber type was sensitized in ASIC3 knock-out mice. The differing impairments in afferent fiber sensitization may be attributable to variations in the function of these channels in different fiber types, such that ASIC3 plays a dominant role in the sensitization of muscular afferents, whereas both TRPV1 and ASIC3 contribute to sensitization in muscular/mucosal afferents. The mechanism by which TRPV1 and ASIC3 mediate afferent fiber sensitization is unknown. Acidification was required because inflammatory soup at neutral $\mathrm{pH}$ only activated afferents and did not also sensitize them. However, the proton-sensing abilities of TRPV1 (Caterina et al., 1997) and ASIC3 (Waldmann et al., 1997) channels in cultured cells is not the sole factor necessary for sensitization because acid alone had no effect on the spontaneous activity or functional properties of colon afferent fibers. A more likely explanation is a G-protein-mediated effect on TRPV1 and ASIC3 channel function by binding of one or more of the acidic inflammatory soup components to their cognate receptors. The activation properties of both TRPV1 and ASIC3 can be potentiated by serotonin and bradykinin via protein kinase C-mediated channel phosphorylation (Premkumar and Ahern, 2000; Deval et al., 2004; Sugiura et al., 2004), and ASIC3 contributes to the hyperexcitability of cultured sensory neurons produced by treatment with inflammatory mediators (Mamet et al., 2002). Additional experiments are needed to determine whether a similar mechanism is responsible for the enhanced mechanosensitivity of colon afferent fibers produced by acidic inflammatory soup.

In summary, we have shown that mice with genetic deletions in either TRPV1 or ASIC3 have significant and selective mechanosensory deficits that affect the function of mechanosensitive colon afferent fibers in the pelvic nerve and pseudaffective behavioral responses to noxious mechanical stimulation of the colon. 
These results support the hypothesis that TRPV1 and ASIC3 contribute to mechanosensation in the viscera and are important mediators of mechanical hypersensitivity produced by tissue insult and injury. Pharmacologic manipulation of TRPV1 and/or ASIC3 may be effective strategies for reducing peripheral contributions to visceral hypersensitivity in human conditions such as irritable bowel syndrome.

\section{References}

Alvarez de la Rosa D, Zhang P, Shao D, White F, Canessa CM (2002) Functional implications of the localization and activity of acid-sensitive channels in rat peripheral nervous system. Proc Natl Acad Sci USA 99:2326-2331.

Birder LA, Kanai AJ, de Groat WC, Kiss S, Nealen ML, Burke NE, Dineley KE, Watkins S, Reynolds IJ, Caterina MJ (2001) Vanilloid receptor expression suggests a sensory role for urinary bladder epithelial cells. Proc Natl Acad Sci USA 98:13396-13401.

Birder LA, Nakamura Y, Kiss S, Nealen ML, Barrick S, Kanai AJ, Wang E, Ruiz G, de Groat WC, Apodaca G, Watkins S, Caterina MJ (2002) Altered urinary bladder function in mice lacking the vanilloid receptor TRPV1. Nat Neurosci 5:856-860.

Brierley SM, Jones III RCW, Gebhart GF, Blackshaw LA (2004) Splanchnic and pelvic mechanosensory afferents signal different qualities of colonic stimuli in mice. Gastroenterology 127:166-178.

Caterina MJ, Schumacher MA, Tominaga M, Rosen TA, Levine JD, Julius D (1997) The capsaicin receptor: a heat-activated ion channel in the pain pathway. Nature 389:816-824.

Caterina MJ, Leffler A, Malmberg AB, Martin WJ, Trafton J, Peterson-Zeitz KR, Koltzenberg M, Basbaum AI, Julius D (2000) Impaired nociception and pain sensation in mice lacking the capsaicin receptor. Science 288:306-313.

Deval E, Salinas M, Baron A, Lingueglia E, Lazdunski M (2004) ASIC2bdependent regulation of ASIC3, an essential acid-sensing ion channel subunit in sensory neurons via the partner protein PICK-1. J Biol Chem 279:19531-19539.

Dinis P, Charrua A, Avelino A, Yaqoob M, Bevan S, Nagy I, Cruz F (2004) Anandamide-evoked activation of vanilloid receptor 1 contributes to the development of bladder hyperreflexia and nociceptive transmission to spinal dorsal horn neurons in cystitis. J Neurosci 24:11253-11263.

Drew LJ, Rohrer DK, Price MP, Blaver KE, Cockayne DA, Cesare P, Wood JN (2004) Acid-sensing ion channels ASIC2 and ASIC3 do not contribute to mechanically activated currents in mammalian sensory neurons. J Physiol (Lond) 556:691-710.

Gebhart GF, Kuner R, Jones RCW, Bielefeldt K (2004) Visceral hypersensitivity. In: Hyperalgesia: molecular mechanisms and clinical implications, progress in pain research and management, Vol 30 (Brune K, Handwerker HO, eds), pp 87-104. Seattle: IASP.

Handwerker HO, Reeh PW (1991) Pain and inflammation. In: Proceedings of the VIth world congress on pain, progress in pain research and clinical management, Vol 4 (Bond MR, Charlton JE, Woolf CJ, eds), pp 59-75. New York: Elsevier.

Kamp EH, Jones III RCW, Tillman SR, Gebhart GF (2003) Quantitative assessment and characterization of visceral nociception and hyperalgesia in mice. Am J Physiol 284:G434-G444.

Lembo T, Munakata J, Mertz H, Niazi N, Kodner A, Nikas V, Mayer E (1994) Evidence for the hypersensitivity of lumbar splanchnic afferents in irritable bowel syndrome. Gastroenterology 107:1686-1696.

Lynn PA, Blackshaw LA (1999) In vitro recordings of afferent fibres with receptive fields in the serosa, muscle and mucosa of rat colon. J Physiol (Lond) 518:271-282.

Lynn PA, Olsson C, Zagorodnyuk V, Costa M, Brookes SJ (2003) Rectal intraganglionic laminar endings are transduction sites of extrinsic mechanoreceptors in the guinea pig rectum. Gastroenterology 125:789-794.

Mamet J, Baron A, Lazdunski M, Voilley N (2002) Proinflammatory medi- ators, stimulators of sensory neuron excitability via the expression of acid-sensing ion channels. J Neurosci 22:10662-10670.

Ness TJ, Gebhart GF (1988) Colorectal distension as a noxious visceral stimulus: physiologic and pharmacologic characterization of pseudoaffective reflexes in the rat. Brain Res 450:153-169.

Page AJ, Brierley SM, Martin CM, Martinez-Salgado C, Wemmie JA, Brennan TJ, Symonds E, Omari T, Lewin G, Welsh MJ, Blackshaw LA (2004) The ion channel ASIC1 contributes to visceral but not cutaneous mechanoreceptor function. Gastroenterology 127:1739-1747.

Page AJ, Brierley SM, Martin CM, Price MP, Symonds E, Butler R, Wemmie JA, Blackshaw A (2005) Different contributions of ASIC channels 1a, 2 and 3 in gastrointestinal mechanosensory function. Gut 54:1408-1415.

Premkumar LS, Ahern GP (2000) Induction of vanilloid receptor channel activity by protein kinase C. Nature 408:985-990.

Price MP, Lewin GR, McIlwrath SL, Cheng C, Xie J, Heppenstall PA, Stucky CL, Mannsfeldt AG, Brennan TJ, Drummond HA, Qiao J, Benson CJ, Tarr DE, Hrstka RF, Yang B, Williamson RA, Welsh MJ (2000) The mammalian sodium channel BNC1 is required for normal touch sensation. Nature 407:1007-1011.

Price MP, Mcllwrath SL, Xie J, Cheng C, Qiao J, Tarr DE, Sluka KA, Brennan TJ, Lewin GR, Welsh MJ (2001) The DRASIC cation channel contributes to the detection of cutaneous touch and acid stimuli in mice. Neuron 32:1071-1083.

Ritchie J (1973) Pain from distension of the pelvic colon by inflating a balloon in the irritable bowel syndrome. Gut 14:125-132.

Rong W, Hillsley K, Davis JB, Hicks G, Winchester WJ, Grundy D (2004) Jejunal afferent nerve sensitivity in wild type and TRPV1 knockout mice. J Physiol (Lond) 560:867-881.

Sluka KA, Price MP, Breese NM, Stucky CL, Wemmie JA, Welsh MJ (2003) Chronic hyperalgesia induced by repeated acid injections in muscle is abolished by the loss of ASIC3, but not ASIC1. Pain 106:229-239.

Su X, Gebhart GF (1998) Mechanosensitive pelvic nerve afferent fibers innervating the colon of the rat are polymodal in character. J Neurophysiol 80:2632-2644.

Sugiura T, Bielefeldt K, Gebhart GF (2004) TRPV1 function in mouse colon sensory neurons is enhanced by metabotropic 5-hydroxytryptamine receptor activation. J Neurosci 24:9521-9530.

Waldmann R, Bassilana F, de Weille J, Champigny G, Heurteaux C, Lazdunski M (1997) Molecular cloning of a non-inactivating proton-gated $\mathrm{Na}^{+}$channel specific for sensory neurons. J Biol Chem 272:20975-20978.

Ward SM, Bayguinov J, Won KJ, Grundy D, Berthoud HR (2003) Distribution of the vanilloid receptor (VR1) in the gastrointestinal tract. J Comp Neurol 465:121-135.

Welsh MJ, Price MP, Xie J (2002) Biochemical basis of touch perception: mechanosensory function of degenerin/epithelial $\mathrm{Na}^{+}$channels. J Biol Chem 277:2369-2372.

Wynn G, Rong W, Xiang Z, Burnstock G (2003) Purinergic mechanisms contribute to mechanosensory transduction in the rat colorectum. Gastroenterol 125:1398-1409.

Yiangou Y, Facer P, Dyer NHC, Chan CLH, Knowles C, Williams NS, Anand P (2001a) Vanilloid receptor 1 immunoreactivity in inflamed human bowel. Lancet 357:1338-1339.

Yiangou Y, Facer P, Smith JAM, Sangameswaran L, Eglen R Birch R, Knowles C, Williams N, Anand P (2001b) Increased acid-sensing ion channel ASIC-3 in inflamed human intestine. Eur J Gastroenterol Hepatol 13:891-896.

Zagorodnyuk V, Brookes SJ (2000) Transduction sites of vagal mechanoreceptors in the guinea pig esophagus. J Neurosci 20:6249-6255.

Zagorodnyuk V, Chen BN, Brookes SJ (2001) Intraganglionic laminar endings are mechano-transduction sites of vagal tension receptors in the guinea pig stomach. J Physiol (Lond) 534:255-268.

Zagorodnyuk V, Chen BN, Costa M, Brookes SJ (2003) Mechanotransduction by intraganglionic laminar endings of vagal tension receptors in the guinea pig esophagus. J Physiol (Lond) 553:575-587. 